\title{
CONSULTA DE ENFERMAGEM GINECOLÓGICA: Eficácia do Tratamento de Rotina nas Vulvovaginites
}

\author{
Carla Luzia França de Araújo * \\ Cláudia Santos **
}

\begin{abstract}
RESUMO - Este estudo tem como objetivo propor as Instituiçōes de Saúde que utilizam o Enfermeiro na realização de consulta ginecológica a adotarem rotina de medicamentos para o tratamento das vulvovaginites. Para isso, obteve-se uma relação dos agentes etiológicos mais freqüentes encontrados no exame colpocitológico, tratamento empregado e uma análise da eficácia deste tratamento de rotina. Considerou-se ainda a freqüência das clientes à consulta de Enfermagem Ginecológica.
\end{abstract}

\begin{abstract}
This study has the objetive of suggesting the Health Institutions, which are used to work with nursing consultation, to adopt a routine of medicines for treating the vulva infections. In order to make.such a treatment, it was obtained a relation between the etymology agents: the ones that are very often found in the female cancer preventive exam, the prescribed treatment and also an analysis of the efficacy of this routine. It was as well considerated the frequency of clients to the gynecological nursing consultation.
\end{abstract}

\section{INTRODUÇĀO}

\subsection{Problema}

Ao realizarmos Consulta de Enfermagem Ginecológica numa Unidade de Cuidados Básicos, nos deparamos com o alto índice de vulvovaginites que eram detectadas após o exame colpocitológico. Ao obterem o resultado dos exames, as clientes recebiam orientações quanto a higiene íntima, e também era feita prescrição de medicamentos de rotina. Desta forma nos perguntamos, qual a eficácia deste ratamento na resolutividade do problema?

\subsection{Justificativa}

De acordo com o Programa de Assistência Integral à Saúde da Mulher ${ }^{5}$ tem-se limitado, quase que, exclusivamente, ao período gravídico-puerperal, e mesmo assim de forma deficiente.

A desatenção aos aspectos integrais da Saúde da Mulher explica também a importância secundária que se dá à profilaxia e terapêutica da morbidade clínica, bem como os fatores ligados ao aparelho reprodutivo, pois apenas $2 \%$ da população feminina é atendida nessa necessidade.
Sendo as vulvovaginites quase sempre causadas por agentes biológicos transmitidos ou não pelo coito. Devido à variedade dos agentes etiológicos, conclui-se que o exame ginecológico é de fundamental importância para o atendimento integral à mulher.

Atualmente, a enfermagem vem aturndo neste campo, realizando consulta de ginecologia primária que consta especificamente de avaliação das mamas e dos órgãos genitais internos e externos. Após a colheita de material vaginal para a realização de citopalogia identificou-se, além de displasias, processos inflamatórios ocasionados por agentes biológicos. Desta forma, para que o atendimento feito pela enfermeira tivesse resolutividade, fez-se necessário estabelecer uma rotina de medicamentos para o tratamento das vulvovaginites mais freqüentes.

Apoiadas na Lei do Exercício Profissional no 7498/86, de 26/06/86, Artigo II, Inciso II, Linea C, e rotina estabelecida pelo Corpo Clinico da Instituição em questão, faz-se a prescrição de acordo com o resultado do exame colpocitológico, juntamente com a orientaçảo de higiene Intima.

* Profeseora Auxiliar de Enfermagem Materno-Infantil. Escola de Enfermagem Anna Nery-UFRJ

* Enfermeira do Hospital Escola Sâa Francisco de Assis HESFA-UFRJ 
Logo ocorre a necessidade de uma avaliação da eficácia destes procedimentos e prescriçōes realizadas pela enfermeira.

\subsection{Objetivos}

\subsubsection{Objetivo Geral}

Propor às Instituições de Saúde que utilizam o enfermeiro na realização de consulta ginecológica a adotarem uma rotina de medicamentos para o tratamento das vulvovaginites.

\subsubsection{Objetivos Específicos}

- Identificar a freqüência das clientes a Consulta de Enfermagem Ginecológica.

- Relacionar os agentes etiológicos encontrados no exame colpocitológico e o tratamento empregado através da prescrição de rotina do creme vaginal.

- Analisar a eficácia do tratamento de rotina das vulvovaginites feito pelo enfermeiro, durante a consulta ginecológica.

\section{RE VISĀO DA LITERATURA}

O programa de Prevenção e Controle do Câncer Cervico-Uterino e de Mama do Munićpio de Resende/RJ ${ }^{6}$, menciona que no Brasil, a cobertura para o exame citológico (Papanicolau) está estimada em $2 \%$ da população feminina no país. Sendo que, em algumas capitais como no Rio de Janeiro, por exemplo, esta cobertura pode alcançar $10 \%$. Quando sabemos que a cobertura estimada pela OMS, para que um programa seja efetivo, é de $85 \%$, entendemos o porque da situação atual do câncer no país.

BRUNNER, SUDDARTH ${ }^{1}$ referem que os tumores malignos do sistema reprodutor feminino (exceto as mamas) respondem pela segunda causa de morte nos Estados Unidos, representando aproximadamente 11.000 mortes por ano. Entretanto, a taxa de morte para o câncer uterino mostrou um declínio constante nos últimos anos, porque mais mulheres estão sendo educadas a fazer um exame anual que inclui um esfregaço de Papanicolau. Entretanto, quando se considera que apenas $53 \%$ das mulheres acima de 20 anos já realizaram um exame Papanicolau, é бbvio que muito permanece por ser feito.

Para que as açōes de prevenção sejam abrangentes é fundamental a descentralização da colheita, na medida em que facilita o acesso das mulheres às Unidades da Rede Básica, promovendo a expansão da cobertura.

De acordo com o MANUAL MERCK ${ }^{3}$ as vulvovaginites são doenças infecciosas e outras condiçōes inflamatórias que afetam a mucosa vaginal e freqüentemente, de modo secundário, envolve a vulva; o corrimento vaginal é comum.

Segundo o Manual de Controle de $\mathrm{DST}^{4}$ as infecçōes estão entre os problemas mais freqüentes ehcontrados nas Consultas Ginecológicas. Embora as complicações médicas resultantes destas infecções sejam raras, a sua freqüência ocasiona desconforto à paciente, limitação da sua capacidade profissional e gastos públicos. Por estas razōes elas são de grande importância para a Saúde Pública.

SOUZA $^{7}$ refere que as infecçōes vaginais podem ser divididas em dois grandes grupos. De um lado, despontam os processos específicos nos quais, em um quadro clínico sugestivo, encontramos um agente etiológico definido. Os representantes deste grupo são a Tricomoníase e a Candidíase. Por outro lado, as vaginites ditas inespecíficas são aquelas em que não existe, na maioria das vezes, um quadro típico associado a determinado agente etiológico. As infecçōes por G. vaginalis seriam as representantes mais comuns deste grupo.

\subsection{Trichomoniase}

Doença infecciosa do trato genito-urinário, normalmente sintomática em mulheres, sendo causada pela Trichomonas vaginalis, microorganismo anaeróbico facultativo predominante de transmissão sexual.

BRUNNER, SUDDARTH ${ }^{1}$ diz que cerca de $5 \%$ a $15 \%$ das mulheres com culturas positivas para Trichomonas são assintomáticas. $\mathrm{O}$ homem pode ser tambem um portador assintomático que abriga os microorganismos no seu trato urogenital e provoca reinfecção de sua companheira.

Segundo o MANUAL MERCK ${ }^{9}$ a trichomoníase é marcada por um corrimento purulento, aquoso, algumas vezes esverdeado, freqüentemente um mau cheiro que começa logo após as menstruações. As bolhas no corrimento, bem como o odor, são provavelmente devido a existência simultânea de uma infecção por bactérias produtores de gás. $\mathrm{O}$ prurido é intenso. Pode ser encontrada inflamação aguda da vagina com pequenos "pontos de morango".

Segundo SOUZA', a droga de escolha é o metranidazol ou derivados. Os esquemas em dose única, $2 \mathrm{~g}$, ou em doses fracionadas mostran-se equivalentes do ponto de vista micro biológico. Devido à facilidade posológica temos preferido o uso em dose única. $O$ esquema a ser adotado é a utilização de metronidazol $500 \mathrm{mg}$., duas vezes ao dia, via vaginal, associado a $2 \mathrm{~g}$., via oral, por dia, durante 7 (sete) - 10 (dez) dias. O tratamento local pode ser administrado em pacientes grávidas que se encontram no $1^{\circ}$ trimestre de gestação.

ELLIS $^{2}$, recomenda que o parceiro sexual 
da paciente seja tratado. A paciente e o parceiro devem ter o cuidado de seguir o tratamento simultâneamente antes de retomarem atividade sexual.

\subsection{Candidlase}

Trata-se da forma mais comum de vulvovaginites encontrada entre a puberdade e a menopausa, isto $e$, durante a vida reprodutiva.

De acordo com ELLIS ${ }^{2}$ é causada pelo fungo Candida Albicans e que é freqüentemente classificada como infecção por "levedura" ou "monnias". A C. albicans é habitante normal da flora vaginal, e nas infecções primárias da vulva a vagina geralmente $e$ a origem da disseminação vulvar. Gravidez, diabetes mellitus, uso de anticoncepcionais orais, terapia com antibióticos são condiçōes estimulantes para o aparecimento da Candíase.

Segundo o MANUAL MERCK ${ }^{3}$, é sugerido por prurido vulvar moderado a grave e sensação de queimação com eritema e possivelmente escoriação. $\mathrm{O}$ corrimento espesso, com aspecto de queijo, que pode estar presente, tende a aderir às paredes vaginais.

De acordo com o Manual de Controle das $\mathrm{DST}^{4}$, o esquema terapêutico é de creme ou comprimido vaginal com nistatina ou derivados, com aplicação diária, durante 14 dias, preferentemente ao deitar. Nos casos mais graves e recidivas, prolongar a terapêutica por 4 (quatro) semanas, tratar o parceiro sexual e investigar as condiçōes a infecção.

SOUZA $^{7}$ recomenda banho e ducha com solução de bicabornato de sódio a 3\%. Outros agentes, como miconazol e o clotrimazol, são também utilizados, sendo que temos preferido utilizá-los como primeira escolha. Estas substâncias mostram índices de cura da ordem $85-90 \%$.

\subsection{Vaginites Inespecíficas}

Em sua grande maioria são ocasior adas pela Gadnerella vaginale, um bacilo Gram-negativo.

O MANUAL MERCK ${ }^{3}$, refere que a in- fecção por Gardnerella tende a produzir secreção esbronquiçada ou amarelada, turva e com desagradável cheiro de peixe, que aumenta quando o corrimento se toma alcalino.

$S O Z^{7}{ }^{7}$ diz que, de maneira geral, o uso da sulfas, tetracidinas ou ampiciline, mostra efetividade que deixa a desejar. Assim, a droga de escolha atualmente $e$ o metronidazol ou seus derivados feito de $2 \mathrm{~g}$ em dose única para o cosal: associando-se creme vaginal a base de mo tronidazol por 14 dias, em aplicação noturna.

\section{METODOLOGIA}

Este estudo é do tipo exploratório, descritivo e quantitativo.

Foi realizado em uma Unidade de Cuidados Básicos de Saúde, de um Hospital Escola do Munić́pio do Rio de Janeiro.

A população abrange mulheres que foram atendidas na consulta de enfermagem ginecologica, selecionadas em amostragem aleatória simples no período de abril a junho de 1991, totalizando 101 clientes.

$O$ instrumento utilizado para a coleta de dados consta de 5 (cinco) perguntas fechadas e 1 (um) quadro que relaciona o agente etiológico e o tratamento utilizado.

A coleta de dados foi utilizada pelas autoras que fizeram levantamento e consulta dos prontuários.

Os dados coletados foram tratados pelo método estatístico descritivo e apresentados em tabelas e quadros, com números absolutos e percentuais, obtidos na tabulação.

\section{APRESENTAÇĀO E ANÁLISE DOS RESULTADOS}

Os dados coletados são apresentados nesth capítulo na forma de quadros e tabelas, usan do-se números absolutos e percentuais.

A amostra foi constituída por 101 prontus rios de clientes analisados pelas pesquisadora A Tabela 1 mostra a faixa etária das clientes atendidas.

Tabela 1 - Faixa etária da clientela atendida na consulta de Enfermagem Ginecológica Rio de Janeiro, 1990.

\begin{tabular}{|c|c|c|c|}
\hline $\begin{array}{l}\text { Faixa Etária } \\
10 \longleftarrow 20 \\
20 \longleftarrow 30 \\
30 \longleftarrow 40 \\
40 \longleftarrow 50 \\
50 \longleftarrow 60 \\
\text { acima de } 60\end{array}$ & $\begin{array}{l}\mathrm{Fi} \\
09 \\
35 \\
36 \\
09 \\
08 \\
04\end{array}$ & $\begin{array}{r}\mathrm{Fi} \% \\
8,9 \\
34,7 \\
35,6 \\
8,9 \\
7,9 \\
4,0 \\
\end{array}$ & . \\
\hline (2) & 101 & 100,0 & \\
\hline
\end{tabular}


A Tabela acima demonstra que $35,6 \%$ das clientes estão na faixa etária de 30 a 40 anos e $34,7 \%$ entre 20 a 30 anos; ou seja, 70,3\% das clientes encontram-se dentro da faixa de idade fértil e vida sexual ativa. O MANUAL MERCK DE MIRDICINA ${ }^{3}$ refere que a etiologia precisa ser considerada por grupos etários, devido às diferenças na atividade sexual e estrogênica. Nos anos reprodutivos, quando o estrogênio se encontra presente, a vulvite 6 em geral secundsria à infecção vaginal.

A tabela 2 nos mostra qual a frequencia das clientes à Consulta de Enfermagem Ginecológica.

Tabela 2 - Distribuição da consulta, segundo o retorno e freqüência das clientes.

\begin{tabular}{l|c|c}
\hline Número de Consultas & $\mathrm{Fi}$ & $\mathrm{Fi} \%$ \\
\hline 02 & 33 & 32,6 \\
03 & 40 & 39,6 \\
04 ou mais & 14 & 13,9 \\
nåo retornaram & 14 & 13,9 \\
\hline & 101 & 100,0 \\
\hline
\end{tabular}

Verifica-se que $39,6 \%$ das clientes compareceram a 3 consultas, $32,6 \%$ a 2 ; porém $13,9 \%$ não retornaram, sendo assim não receberam o

resultado do exame colpocitológico e foram excluídas do presente estudo.

Tabela 3 - Clientes com diagnóstico inflamatório no exame colpocitológico.

\begin{tabular}{|c|c|c|}
\hline $\begin{array}{l}\text { Resultado } \\
\text { Inflamatório }\end{array}$ & $\mathrm{Fi}$ & $\mathrm{Fi} \%$ \\
\hline Sim & 87 & 100,0 \\
\hline Nāo & $\frac{-}{87}$ & $\frac{-}{100,0}$ \\
\hline
\end{tabular}

Como podemos ver na Tabela 3, 100,0\% das clientes apresentam resultado do exame ginecológico com diagnóstico inflamatório.

De acordo com SOUZA ${ }^{7}$, hoje é universalmente aceito que a tricomoníase, a candidíase e os corrimentos associados a G. vaginalis respondem por mais de $90 \%$ dos casos vaginites de causa infecciosa; como podemos observar na Tabela abaixo.

Tabela 4 - Distribuição dos agentes etiológicos encontrados no exame colpocitológico da clier tela pesquisada.

\begin{tabular}{|c|c|c|}
\hline Agente etiológico & $\mathrm{Fi}$ & $\mathrm{Fi} \%$ \\
\hline Tnflamatório Inespecifico & 12 & 14,2 \\
\hline Flora bacteriana mista & 15 & 17,9 \\
\hline Gardnerella vaginalis & 15 & 17,9 \\
\hline Trichomonas vaginalis & 23 & 27,4 \\
\hline Candida albicans & 19 & 22,6 \\
\hline . & 84 * & 100,0 \\
\hline
\end{tabular}

* Foram excluídas 3 (três) clientes pois apresentaram diagnóstico de displasia, sendo encaminhada à Unidade de Referência.

Notamos que $27,4 \%$ apresenta como agente etiológico o $\mathrm{T}$. vaginalis e $22,6 \%$ pela $\mathrm{C}$. albicans.
De acordo com rotina estabelecida na Instituição de Saúde em questão e os resultados dos exames colpocitológicos foi feita a prescrição dos medicamentos; como podemos constar na Tabela 5. 
Tabela 5 - Agentes etiológicos encontrados no exame colpocitológico e o tratamento empregado.

\begin{tabular}{|c|c|c|c|c|c|c|c|c|c|c|}
\hline \multirow{2}{*}{$\begin{array}{l}\text { Agente etiológico } \\
\text { Creme vaginal }\end{array}$} & \multicolumn{2}{|c|}{$\begin{array}{l}\text { Inflamatório } \\
\text { Inespecifico }\end{array}$} & \multicolumn{2}{|c|}{$\begin{array}{c}\text { Flora } \\
\text { Bacteriana }\end{array}$} & \multicolumn{2}{|c|}{$\begin{array}{c}\text { Gardenerella } \\
\text { Vaginalis }\end{array}$} & \multicolumn{2}{|c|}{$\begin{array}{c}\text { Trichomononas } \\
\text { Vaginalis }\end{array}$} & \multicolumn{2}{|c|}{$\begin{array}{l}\text { Candida } \\
\text { Albicans }\end{array}$} \\
\hline & $\mathrm{Fi}$ & $\mathrm{Fi} \%$ & $\mathrm{Fi}$ & $\mathrm{Fi} \%$ & $\mathrm{Fi}$ & $\mathrm{Fi} \%$ & $\mathrm{Fi}$ & $\mathrm{Fi} \%$ & $\mathrm{Fi}$ & $\mathrm{FT} \%$ \\
\hline $\begin{array}{l}\text { tetraciclina + } \\
\text { Anfotericina B }\end{array}$ & 09 & 75,0 & 14 & 93,3 & 10 & 66,7 & - & - & - & - \\
\hline $\begin{array}{l}\text { Sulfatiazol + } \\
\text { Sulfacetamida + } \\
\text { Sulfabenzamida }\end{array}$ & - & - & 01 & 6,7 & 04 & 26,7 & - & - & - & - \\
\hline Metronidazol & 01 & 8,3 & - & - & - & - & 16 & 66,7 & - & - \\
\hline Nistatina & - & - & - & - & - & - & - & - & 17 & 94,4 \\
\hline $\begin{array}{c}\text { Tinidazol + } \\
\text { Miconazol }\end{array}$ & - & - & - & - & - & - & 08 & 33,3 & - & - \\
\hline $\begin{array}{l}\text { Clorafenicol } \\
\text { Nistatina + }\end{array}$ & 02 & 16,7 & - & - & - & - & - & - & - & - \\
\hline $\begin{array}{l}\text { Nistatina + } \\
\text { Metronidazol }\end{array}$ & - & - & - & - & - & - & - & - & 01 & 5,6 \\
\hline Tinidazol & - & - & - & - & 01 & 66 & - & - & - & - \\
\hline$\Sigma$ & 12 & 100,0 & 15 & 100,0 & 15 & 100,0 & 24 & 100,0 & 18 & 100,0 \\
\hline
\end{tabular}

Após ter sido realizado o tratamento prescrito, as clientes foram submetidas a exame col- pocitológico de controle, onde obtivemos os seguintes resultados, relacionados na Tabela 6.

Tabela 6 - Eficácia do Tratamento, verificado com exame colpocitológico de controle.

\begin{tabular}{l|c|c}
\hline $\begin{array}{l}\text { Resultado do exame } \\
\text { colpocitológico de controle }\end{array}$ & Fi & Fi \% \\
\hline Ausência do agente etiológico & 62 & 86,1 \\
Presença do agente etiológico & 10 & 13,9 \\
\hline$\Sigma$ & 72 & 100,0 \\
\hline
\end{tabular}

Como podemos observar $86,1 \%$ dos resultados foram negativos, ou seja, ausência de agentes etiológicos e apenas $13,9 \%$ dos agentes encontrados anteriormente persistiam ao tratamento instituído na rotina.

\section{CONCLUSĀO E SUGESTŌES}

Ao final deste trabalho, conclui-se que:

- A freqüência na Consulta de Enfermagem é alta, o que nos leva a crer que as clientes têm suas expectativas atendidas pelo enfermeiro.

- Os agentes etiológicos mais freqüentes são: $T$. vaginalis, C. albicans e G. vaginalis.

- $O$ elevado índice de vulvovaginites iden- tificados pelo enfermeiro após o resultådo do exame colpocitológico.

- A alta eficácia do tratamento de rotina estabelecido.

Após o exposto sugere-se:

- Ás Escolas de Enfermagem capacitarem os Enfermeiros para realizarem Consulta de Eniermagem em Gínecologia Primária;

- Ass Instituiçōes de Saúde estabelecer rotinas de medicamentos para serem utilizadas pelo Enfermeiro durante a Consulta Ginecológica.

- Ás Instituiçōes de Saúde possibilitarem o treinamento em serviço do Enfermeiro.

- A os Enfermeiros se empenharem em executar a Consulta de Enfermagem como atividade fim.

\section{REFERÊNCIAS BIBLIOGRÅFICAS}

1 BRUNNER, Lilian Sholtis, SUDDAR TH, Doris Smith - Enfermagem Médico-Ciruígico. Rio de Janeiro: Interamericana, 1982 V. 3.

2 ELLIS, Jeffrey W., BECKMAN, Charles R.B. Manual de Ginecologia. Rio de Janeiro: Prentice-Hall do Brasil, 1986.

3 MANUAL MERCK DE MEDICINA: Diagnbstico e Tratamento. Såo Paulo: Roca - Robert Berkow, Editor-
Chefe, 1989.
4 MINIS TÉRIO DA SAÚDE. Controle de Doenças Sexualmente Iransmiss/veis. Brasnia, Centro de Documenteç̊̊, 1985.

5 - Programa de Assistencia Integral à Saćde da Mulher. Brasnia, Centro de Documenitaģă, 1986.

6 PREFEITURA MUINICIPAL DE RESENDE. Programs de Prevençăo e Controle do Cencer Cérvico-uterino e de Mams. Resende, 1990.

7 SOUZA, Aurelio Zacche de. Terapiutica Ginecolbgica. Ssa. Paulo: Roca, 1988. 
Instrumento de Coleta de Dados.

No PRONTUÁRIO:

IDADE (em anos):

Retorno à Consulta Subseqüente

( ) Sim ( ) Não

Número de Consultas:

01 consultas

02 consultas

03 consultas ou mais

Resultado do exame colpocitológico:

inflamatório

negativo

Agente infeccioso diagnosticado:

Tratamento prescrito:

Resultado do exame colpocitológico de controle:

inflamatório

negativo

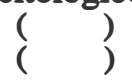

Tratamento prescrito $\mathrm{x}$ Agente identificado no resultado colpocitologico.

\begin{tabular}{l|l|l|l|l|l}
\hline \multicolumn{1}{c|}{ Etiologia } & Inespecifico & $\begin{array}{c}\text { Flora } \\
\text { Bacteriana }\end{array}$ & Gardenerella & Trichomonas & $\begin{array}{c}\text { Candida } \\
\text { Albincans }\end{array}$ \\
\hline $\begin{array}{l}\text { Tetraciclina + Anfotericina B } \\
\begin{array}{l}\text { Sulfatiazol + Sulfacetamida } \\
+ \text { Sulfabenzamida }\end{array}\end{array}$ & & & & & \\
\hline Metronidazol & & & & & \\
\hline Nistatina & & & & & \\
\hline Tipidazol + Miconazol & & & & & \\
\hline Clorafenicol & & & & & \\
\hline Nistatina + Metronidazol & & & & & \\
\hline Tinidazol & & & & & \\
\hline
\end{tabular}

Casos de Displasia:

Resultados após Tratamento:

ausência do Agente ()

presença do Agente () 